\title{
Experimental investigation of zero energy office under natural and forced ventilation
}

\author{
Hussain H. Al-Kayiem ${ }^{1}$, Syed I. U. Gilani ${ }^{1,}{ }^{*}$ and Mahmoud S. Abdalfatah ${ }^{2}$ \\ ${ }^{1}$ Mech. Eng. Dept., Universiti Teknologi PETRONAS, 32610 Bandar Seri Iskandar, Malaysia \\ ${ }^{2}$ Smart Tech Solution, 1/15A Third Settlement, Industrial Zone, New Cairo, Cairo, Egypt
}

\begin{abstract}
With the rapid rise of energy consumption in the world, lowering the energy needs of houses and buildings can have a significant effect on future of energy demand and consumption. This paper presents experimental investigation results on the effectiveness of the natural and forced ventilation in prototype of zero-energy office. The main aim of the different ventilation systems is to improve the thermal comfort within the office. The installed forced ventilation system achieved a $6^{\circ} \mathrm{C}$ drop in maximum temperature within the office and improved the thermal comfort by $46 \%$.
\end{abstract}

\section{Introduction}

The residential sector accounts for approximately $18 \%$ of the global energy usage with an expected annual increase rate of $1.5 \%$ [1]. Hence, lowering the energy needs of the houses and buildings is vital to decrease the energy consumption and increase the dependence on renewable energy sources. It is found that up to $66 \%$ energy savings could be achieved in the household annual energy consumption by using net zero-energy building (nZEB) methods to optimize air flow through the usage of passive design techniques [2].

\subsection{Concept of net zero-energy building}

Many definitions have been put forward by researchers to define what exactly is nZEB and how to measure their performance. A proper technical consistent classification is required for countries and unions to align their ambitions and plans and set KPIs. This is what pushed the Federation of European Heating, Ventilation and Air Conditioning Association (REHVA) to decide on one technical definition to be used all across Europe. The research was led by [3] in 2013 to define nZEB as "A building that has very high energy performance. The nearly zero or very low amount of energy required should be covered to a very significant extent by energy from renewable sources, including energy from renewable sources produced on-site or nearby.

The definition adopted by the REHVA follows "avoided burden" logic. In this perspective the building is defined as nZEB because it avoids the need for primary energy that would otherwise have been needed to keep the building running.

- Corresponding author: syedihtsham@utp.edu.my 
There are many methods by which the energy balance could be calculated within the avoided burden approach. [4] presents four methods for such calculations namely, a) Site balance b) Source energy balance c) Source energy balance with building embodied energy c) Source energy balance with RES embodied energy. A source energy balance is done at the primary energy level and termed ZEB source. This balance method is highly recognized by the international community.

nZEB must be optimized to consume very little energy so that a big part of the energy needed can be generated by the renewable sources installed within the building. Minimizing the energy usage of the building can be achieved using passive design techniques or energy efficient technologies or a hybrid of both. Passive design techniques mainly focus on using the building design to reduce the energy consumption (see figure 1). Passive design techniques include using the building's envelop, orientation and geometric and ratios to reduce the energy needed to power the building [5]. A major objective of passive design techniques is to use isolation to keep the building temperature stable and to use natural ventilation to provide the thermal comfort needed. On the other hand, using energy efficient technologies lowers the total energy usage by using higher efficiency HVAC systems, appliances and lighting. A hybrid solution aims at using both techniques to lower the energy needs of the building.

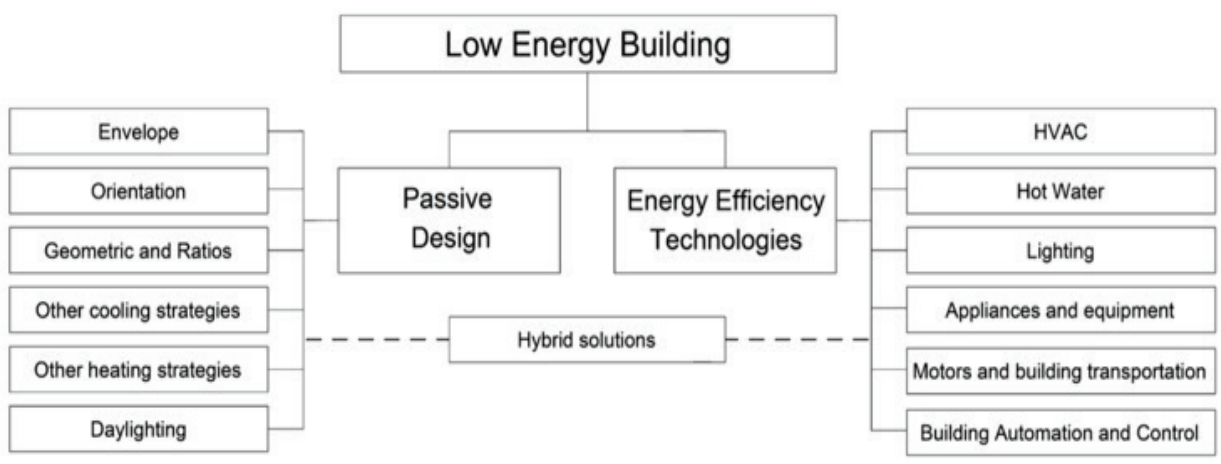

Fig. 1. Low energy building techniques. [5]

A buoyancy-driven natural ventilation system uses the difference in air density resulting from different air temperature to generate airflow. When the building's indoor temperature is higher than the outdoor temperature, the cold, high density, air from outside enters the building at lower floors. At the same time, the hot, low density, air at lower floors, inside the building rises up to higher floors where it exits. Thus the lower floor windows allow air to come in, which then exits from the upper floor creating airflow within the building; such phenomenon is called the "stack effect". The different in pressure between the two sides of the window, resulting from the difference in temperature and thus difference in density, controls whether air enters the building or flow out of it.

In a multi floor building, the top opening is made to be the larger than all the other windows in the building. This design assures that the neutral pressure plane is higher than the top floor, thus there is no recirculation of air within the building. Increasing the window to wall ratio to 0.24 can increase thermal condition indoor [6]. Furthermore, a recommended total area of inlet and outlet apertures is about $40 \%$ [7]. Figure 2, shows how the stack effect is implemented in a building with an atrium [8]. Airflow of cold air turns into hot air before exiting the building at the top chimney through the atrium. The design of the building and the implementation of the atrium can be adapted differently to suit the different conditions for different buildings. 


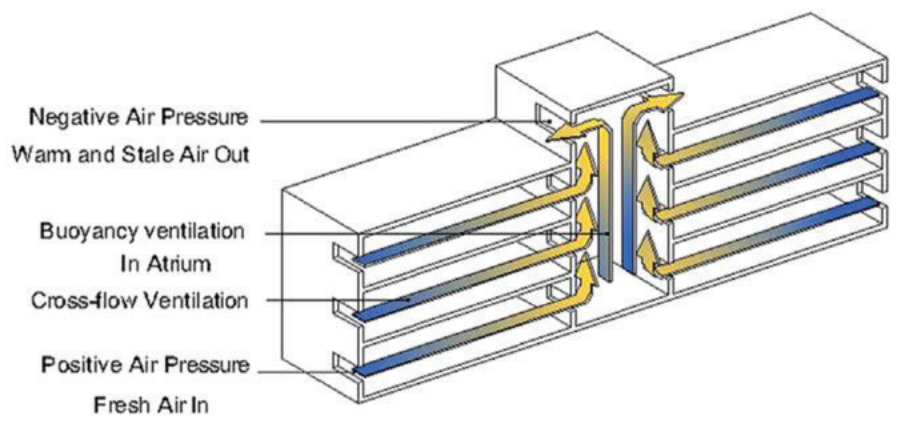

Fig. 2. Principles of stack effect in envelop of building [8]

\subsection{Thermal comfort within the office}

The ultimate objective of using the solar chimney is to achieve thermal comfort within the building while reducing the energy consumption. Although thermal comfort is a very subjective state, the acceptable levels of thermal comfort are specified in ASHRAE building standards. The standard way of measuring the thermal comfort within a building is by conducting a survey whether the condition within the building is comfortable or not. After extensive research and hundreds of conducted surveys, ASHRAE has released a method to calculate the Predicted Mean Vote (PMV). PMV is a standard measurement of thermal comfort within any building and ASHRAE [9] releases standard values of PMV measurement that offices and public buildings must adhere to. Furthermore, the PMV can be calculated based on the temperature of air within the building, the mean radiant temperature the occupants feel, air speed, relative humidity level, metabolic rate and clothing level. While the PMV model predicts thermal sensation well in buildings with HVAC systems, field studies in warm climates in buildings without air-conditioning have shown that it predicts a warmer thermal sensation than the occupants actually feel [10]. It's for this reason that Fanger et al. have introduced a way to adjust the PMV values from the standard ASHRAE calculation to be closer to the measured PMV in warm climates countries where the buildings are without air-conditioning [11].

The currently implemented Zero Energy office in UTP is using a natural ventilation system to achieve temperature comfort needed within the building. The house studied in this project uses a buoyancy-driven natural ventilation system. The problem at hand is to confirm whether the installed ventilation system is sufficient to achieve thermal comfort within the building.

The objective of the current work is to carry out monitoring and measurement on the office to evaluate and compare the effectiveness of different ventilation procedures at achieving thermal comfort within the office.

- The ventilation procedure either natural or forced.

- Monitoring the effect of the ventilation system on the level of thermal comfort within the office.

- Monitoring $\Delta \mathrm{T}$ and $\Delta \mathrm{RH}$ between indoors and outdoors.

In this project the adjusted PMV model developed by Fanger will be adapted. A recommended expectancy factor of 0.7 will be used. An expectancy factor of 0.7 has been adopted in Singapore and getting a very accurate expectation of PMV. Fanger's adjusted PMV model predicts the thermal comfort response of the occupants in hot weather accurately 


\section{METHODOLOGY}

This project is concerned with the zero-energy office prototype. The building prototype consists of the office room, a hallway where cross wind flows and a third room that is of no interest to the project at hand. Figure 3 shows how natural ventilation happens in the office prototype.

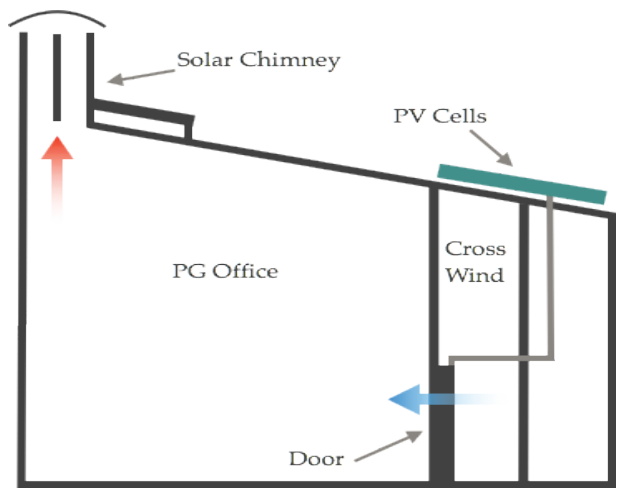

Fig. 3. Schematic of the Zero-energy office

The cold air enters the office from the open door. The hallway, where the cross winds acts, is the main source of fresh air in this case. The solar chimney at the top helps to heat up the air at the top levels thus acting as an area of low pressure to suck up the stagnant air to outside the building.

The methodology in this project is to experimentally measure the effectiveness of the natural ventilation system. The effectiveness is indicated by an increased thermal comfort. The experiments were designed to track the change in the temperature within the building during the day and during the night. Another factor to be experimentally evaluated is the change in humidity throughout the day. Lastly the airflow rate will be measured. With measurement results at hand, the effectiveness of the system at increasing the thermal comfort could be evaluated. A higher airflow rate between the inside and outside of the building is preferred. The temperature and humidity level in the building should always lie within the comfort levels throughout the day. If the system is not effective enough, a reevaluation of the design of the natural ventilation system is needed. Such effort could be carried out separately in a different project. Figure 4 shows the measurement tools installation placement at the site.
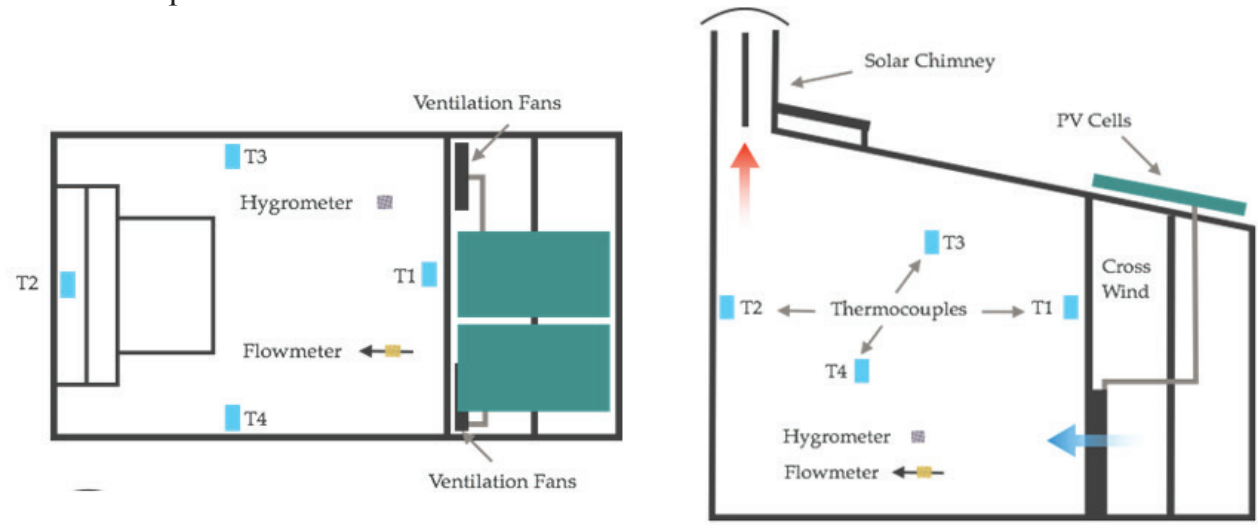

Fig. 4. Testing the effectiveness of natural and forced ventilation systems. 
The two most critical variables, to calculate the thermal comfort, in accordance with Fanger's equation, are air temperature inside the office, radiant temperature sensed by the occupant and air flow within the office. Thermocouples T1 and T2 are used to measure the air temperature inside the office. The average of T1 and T2 was used as the average air temperature within the office. The average radiant temperature inside the office, the average of T3 and T4 was considered.

The forced ventilation system is comprised of four solar fans that are powered by PV cells. The fans are used to increase the air rate of change in the office. The forced flow of air caused by the fans will aid the ventilation system and stack effect. The usage of the forced ventilation system will only happen after measuring the effectiveness of the ventilation under the natural ventilation only. The experiment is to be carried out once without any active ventilation systems. The resulting data will be taken as a benchmark to measure the progress against. Secondly, data will be collected with active natural ventilation system exclusively. Lastly, the experiment is to be carried out with both natural and forced ventilation system working in tandem.

Three different cases have been experimented. Each experiment has been repeated 4 days and the mean is considered in the presentation and discussion of results.

Table 1. Identifications of the measurement cases

\begin{tabular}{|c|l|l|}
\hline case & Ventilation status & \multicolumn{1}{c|}{ Conditions and description of the case. } \\
\hline Case-1 & Natural ventilation & $\begin{array}{l}\text { No in flow. The building locked and sealed. Only inlet to the } \\
\text { solar chimney is operated. }\end{array}$ \\
\hline Case-2 & Natural ventilation & Flow through the opened door. And exit to the chimney inlet. \\
\hline Case-3 & Forced ventilation & $\begin{array}{l}\text { 4 solar fans are operating to bring ambient air to inside the } \\
\text { office. Exit to the solar chimney is opened. }\end{array}$ \\
\hline
\end{tabular}

\section{Results and discussion}

\section{Case-1: No active ventilation system}

In case-1, the door was closed to deactivate any possible ventilation. Thus follows the first set of data collected with a closed door, i.e., no active ventilation system. Table 2 shows the maximum and minimum thermal comfort points. The predicted adjusted thermal comfort PMV at highest temperature is 5.65, which indicates too hot conditions. At the lowest temperature, during the measurement period, the Adjusted Thermal Comfort PMV is 0.61 which indicating slightly warm. Results of case- 1 show how the spaces inside the office can heats up to very high temperature without any ventilation system at work. This is the normal state at which the office would be at without any of the ZEB techniques applied to aid in the ventilation of the space. With a maximum radiant temperature of $49^{\circ} \mathrm{C}$, the space had a very poor rating of thermal comfort of 5.65 which is considered too hot according to ASHRAE-55 standards. Since the ASHRAE-55 scale extends from -3 to +3 , the resulting thermal comfort in this case is off the chart. The space is simply very uncomfortable to stay in at such state.

Table 2. Maximum and minimum thermal comfort as measured for case-1

\begin{tabular}{|c|c|c|c|}
\hline Time & $\begin{array}{c}\text { Average Air } \\
\text { Temperature }\left({ }^{\circ} \mathrm{C}\right)\end{array}$ & $\begin{array}{c}\text { Average Radiant } \\
\text { Temperature }\left({ }^{\circ} \mathrm{C}\right)\end{array}$ & $\begin{array}{c}\text { Adjusted Thermal Comfort } \\
\text { PMV }\end{array}$ \\
\hline 5:15 PM & 45.93 & 49.34 & 5.65 (Too Hot) \\
\hline $7: 30 \mathrm{AM}$ & 28.47 & 27.27 & 0.61 (Slightly Warm) \\
\hline
\end{tabular}




\section{Case-2: Active natural ventilation system}

In this case, the door was open to allow natural ventilation system to refresh the air within the office. The mean data of 4 days is shown in table 3, where only particulars of thermal comfort at maximum and minimum temperatures are presented. At the maximum point, the radiant temperature reached $48.16^{\circ} \mathrm{C}$ while the air temperature is top at $43.67^{\circ} \mathrm{C}$. The following table shows the predicted thermal comfort based on maximum and minimum measurement for this set of data. In case-2, the doors were open thus the air was allowed to flow in the house and exit through the solar chimney at the top of the house. This natural ventilation system aids in getting the air to circulate through the office. This ventilation system is purely passive and costs nothing but the initial cost of setup for the solar chimney. Natural ventilation systems are valuable since they can improve thermal comfort, although marginally, without using any mechanical systems. The natural ventilation system dropped the temperature by $2^{\circ} \mathrm{C}$ and improved the thermal comfort level by $9 \%$. Although the thermal comfort level is still far away from the recommended range by ASHRAE, the 9\% increase at no additional operating cost and with only a solar chimney installed on top of the office is effective.

Table 3. Maximum and minimum thermal comfort as measured for case- 2

\begin{tabular}{|c|c|c|c|}
\hline Time & $\begin{array}{c}\text { Average Air } \\
\text { Temperature }\left({ }^{\circ} \mathrm{C}\right)\end{array}$ & $\begin{array}{c}\text { Average Radiant } \\
\text { Temperature }\left({ }^{\circ} \mathrm{C}\right)\end{array}$ & $\begin{array}{c}\text { Adjusted Thermal Comfort } \\
\text { PMV }\end{array}$ \\
\hline 6:00 PM & 41.84 & 44.06 & 5.80 (Too Hot) \\
\hline 8:15 PM & 33.99 & 32.89 & 1.9 (Slightly Warm) \\
\hline
\end{tabular}

\section{Case-3: Active natural and forced ventilation systems}

In this last experiment the ventilation fans were turned on. This was the natural ventilation system and the forced ventilation system was both working concurrently. The ventilation fans allow for more airflow within the office and hence lower temperatures are expected. Figure 11 shows the resulting data from the last experiment where the maximum ventilation occurred. The drop in the maximum temperature is noticeable clearly. The thermal comfort throughout the day was also improved. Following are the data for the thermal comfort.

Table 4. Maximum and minimum thermal comfort as measured for case-3

\begin{tabular}{|c|c|c|c|}
\hline Time & $\begin{array}{c}\text { Average Air } \\
\text { Temperature }\left({ }^{\circ} \mathrm{C}\right)\end{array}$ & $\begin{array}{c}\text { Average Radiant } \\
\text { Temperature }\left({ }^{\circ} \mathrm{C}\right)\end{array}$ & $\begin{array}{c}\text { Adjusted Thermal } \\
\text { Comfort PMV }\end{array}$ \\
\hline 2:15 PM & 38.89 & 40.39 & 3.47 (Too Hot) \\
\hline $8: 15 \mathrm{PM}$ & 31.04 & 30.13 & 1.33 (Slightly Warm) \\
\hline
\end{tabular}

The results show progression improvement in thermal comfort from one experiment to another. In case- 3 the ventilation fans were turned on for 24 hours a day. The ventilation fans run on $12 \mathrm{VDC}$ coming from the battery which is connected to the solar panels on top of the office. The four ventilation fans aided the air flow greatly throughout the office and helped improve thermal comfort significantly. Although the ventilation fans don't consume any grid energy, the energy embedded in fabricating the PV panels is considerable. The installation of the PV panels and the ventilation fans might be costly, yet the resulting data are encouraging. With the forced ventilation working side by side with natural ventilation the maximum temperature dropped by $6^{\circ} \mathrm{C}$ and the thermal comfort improved by $46 \%$. 
Such improvement in thermal comfort is highly significant. At best the thermal comfort was very close to accepted levels within the ASHRAE-55 standards while at worst, the PMV was slightly overshooting the scale at 3.47.

\section{Conclusion}

ZEB has been investigated experimentally at three different cases to evaluate the level of comfort. Solar fans have been used to impose forced ventilation and solar chimney has been used to enhance the natural ventilation. The ultimate aim of any ventilation system is to provide thermal comfort within the building. Hence, the effect of the installed systems on the thermal comfort levels within the building is the focus point of this project. With three experiment conducted under three different settings, the results show a promising improvement in thermal comfort levels.

While using the natural ventilation system exclusively decreased the maximum temperature by $2^{\circ} \mathrm{C}$, using the forced ventilation system decreased the maximum temperature by $6^{\circ} \mathrm{C}$ and consequently improved the thermal comfort by $46 \%$. Nevertheless, the resulting thermal comfort levels are not within the accepted range recommended by ASHRAE-55 standards. This calls for more passive and/or active ventilation techniques to improved thermal conditions in the office envelope. Live green wall is seems to be active technique to reduce the solar radiation absorption by the walls of the office. Since most of the heat is transferred to the office through the wide glass windows, it is recommended to shade the windows or cover them by insulation material.

The authors acknowledge Universiti Teknologi PETRONAS for supporting the work, logistically and financially. Also, the authors acknowledge the Ministry of Higher Education of Malaysia (MOHE) for allowing the use of the equipment under project FRGS/1/2017/STG02/UTP/01/1.

\section{References}

1 L. Pérez-Lombard, J. Ortiz, C. Pout, ENB 40, 394-398. (2007)

2 Yuanming Kwan, Lisa Guan, Procedia Engineering, 121, 604-611(2015)

3 J. Kurnitski, F. Allard, D. Braham, D. van Dijk, C. Feldman, J. Fox, REHVA nZEB. Technical Report, REHVA, (2013).

4 J. S. Bourrelle, I. Andresen, Arild Gustavsen, ENB 65, Pages 84-92 (2013)

5 E. Rodriguez-Ubinas, C. Montero, M. Porteros, S. Vega, I. Navarro, M. CastilloCagigal, E. Matallanasc, A. Gutiérrez, ENB 83, 10-22. (2014)

6 W. Liping, W. N. Hien, Building and Environment 42. 4006-4015. (2007)

7 C. Tantasavasdi, J. Srebric, Q. Chen, ENB 33. 815-824. (2001)

8 L. Moosavi, N. Mahyuddin, N. Ab Ghafar, M. A. Ismail, RSER 34, Pages 654-670 (2014)

9 ASHRAE Handbook 2017-Fundamentals, Chapter 9, Thermal Comfort. (2017)

10 G. S. Brager and R. de Dear, ENB 27. 83-96. (1998)

11 P. Ole Fanger, J. Toftum, ENB 34, (6), 533-536 (2002) 